\title{
Theoretical modelling of epigenetically modified DNA
}

\section{sequences [version 1; peer review: 1 approved, 1 approved}

\section{with reservations]}

\section{Alexandra Teresa Pires Carvalho1, Maria Leonor Gouveia1,2, Charan Raju Kanna1, Sebastian K. T. S. Wärmländer ${ }^{3}$, Jamie Platts ${ }^{4}$, Shina Caroline Lynn Kamerlin ${ }^{1}$}

\author{
${ }^{1}$ Science for Life Laboratory, Department of Cell and Molecular Biology, Uppsala University, Uppsala, S-751 24, Sweden \\ 2Department of Immunology, Genetics and Pathology, Rudbeck Laboratory, Uppsala, S-751 85, Sweden \\ ${ }^{3}$ Department of Biochemistry and Biophysics, Stockholm University, Stockholm, S-106 91, Sweden \\ ${ }^{4}$ d. School of Chemistry, Cardiff University, Cardiff, CF10 3AT, UK
}

\author{
V1 First published: 24 Feb 2015, 4:52 \\ https://doi.org/10.12688/f1000research.6148.1 \\ Latest published: 06 May 2015, 4:52 \\ https://doi.org/10.12688/f1000research.6148.2
}

\section{Open Peer Review}

Approval Status

1 2

version 2

(revision)

06 May 2015

version 1

24 Feb 2015

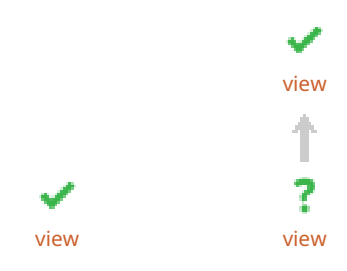

1. Célia Fonseca Guerra, VU University

Amsterdam, Amsterdam, The Netherlands

2. Katja Petzold, Karolinska Institute,

Stockholm, Sweden

Any reports and responses or comments on the article can be found at the end of the article. 
epigenetic modifications within realistic molecular contexts.

Keywords

Epigenetics, DNA modifications, DNA methylation, Density functional

theory, hybrid QM/MM calculations, DNA model systems

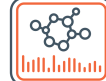

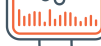

This article is included in the Bioinformatics

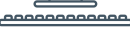

gateway.

Corresponding authors: Jamie Platts (platts@cardiff.ac.uk), Shina Caroline Lynn Kamerlin (kamerlin@icm.uu.se)

Competing interests: No competing interests were disclosed.

Grant information: This work was supported by the Swedish Research Council (Vetenskapsrådet, 2010-5026) and funding from the Sven and Ebba Christina Hagbergs Foundation.

The funders had no role in study design, data collection and analysis, decision to publish, or preparation of the manuscript.

Copyright: ( 2015 Carvalho ATP et al. This is an open access article distributed under the terms of the Creative Commons Attribution License, which permits unrestricted use, distribution, and reproduction in any medium, provided the original work is properly cited. Data associated with the article are available under the terms of the Creative Commons Zero "No rights reserved" data waiver (CC0 1.0 Public domain dedication).

How to cite this article: Carvalho ATP, Gouveia ML, Raju Kanna C et al. Theoretical modelling of epigenetically modified DNA sequences [version 1; peer review: 1 approved, 1 approved with reservations] F1000Research 2015, 4:52

https://doi.org/10.12688/f1000research.6148.1

First published: 24 Feb 2015, 4:52 https://doi.org/10.12688/f1000research.6148.1 


\section{Introduction}

The standard four-letter alphabet used to encode genetic information in DNA is a central tenet of molecular biology. However, in vivo chemical modification of bases can expand this alphabet markedly, giving rise to a host of important biological phenomena ${ }^{1}$. Epigenetic modifications, most importantly DNA methylation and histone variation, have the potential to affect gene expression, and are believed to play a major role in the complex pattern of development and differentiation of multi-cellular organisms. Fascinatingly, such modifications may be heritable despite not affecting DNA sequence, although the mechanism(s) by which this could be achieved are currently unknown.

The most common and biologically important such modification involves methylation of the 5 position of cytosine $(\mathrm{C})$ to form 5-methylcytosine $(5-\mathrm{mC})$, illustrated in Figure 1. This does not strongly affect the ability of the base to pair with guanine $(\mathrm{G})$, and in mammals is generally found in $\mathrm{CpG}$ sequences, though bacteria and plants display less sequence specificity ${ }^{2}$. Oxidation of 5-mC can form 5-hydroxymethylcytosine (5-hmC), which is believed to be involved in regeneration of C via ten-eleven translocation (TET) proteins. Moreover, recent work has shown that 5-formylcytosine (5-fC), and 5-carboxycytosine (5-caC) are present in stem cells and organs of mice ${ }^{3}$.

The structural consequences of cytosine methylation and related modifications were the focus of a recent study ${ }^{4}$ that used X-ray crystallography to show that incorporation of 5-mC or 5-hmC at different points in the d(CGCGAATTCGCG) dodecamer has a negligible effect on both local (base pair) and global (helical) geometry, although specific preference for the orientation of the hydroxyl group in the latter was clearly evident. However, while elegant, the resolution of these studies (between 1.42 and $1.99 \AA$ ) may mean that subtle structural changes could go unnoticed. Therefore, molecular modelling, whether based on quantum or classical mechanics,<smiles></smiles><smiles>Cc1c[nH]c(=O)nc1N</smiles><smiles>Nc1nc(=O)[nH]cc1CO</smiles><smiles>Nc1nc(=O)[nH]cc1C=O</smiles><smiles>Nc1nc(=O)[nH]cc1C(=O)O</smiles>

Figure 1. Structures of cytosine and its epigenetic modifications. has the potential to contribute significantly in this field. Quantum mechanical models, typically using density functional theory (DFT), have been used to examine the base pairing and stacking of both unmodified (wild-type) and 5-mC DNA. Many groups, including those of Fonseca-Guerra ${ }^{5-7}$, Šponer ${ }^{8-13}$, Leszczynski ${ }^{14-16}$ and others have used DFT to great effect in understanding the structure and properties of unmodified DNA. Regarding epigenetic modifications in particular, Acosta-Silva et al. ${ }^{17}$ showed in this manner that methylation enhances stacking interactions, and can produce local distortions in base-pair step parameters, most notably slide. Yusufaly et al. used similar calculations to show that methylation can induce over-twisting as well as softer modes for distortion from the global energy minimum ${ }^{18}$. We recently employed classical mechanics to examine not only the structure but also the flexibility of different DNA sequences with methyl and hydroxymethyl substituents ${ }^{19}$. Through use of extended molecular dynamics (MD) simulations, we showed that structural effects are subtle, but that epigenetic modifications can give rise to changes in twist, roll and tilt angles that are markedly sequence-dependent. Moreover, introduction of 5-mC within a sequence that already contains hydrophobic groups in the major groove strongly affects hydration patterns, whereas an isolated 5-mC has a lesser effect on solvation and structure.

In this work, we use DFT and QM/MM methods to examine model systems containing modified cytosines. These range from individual base pairs, through double-stranded trimers, to heptamers. By including the sugar-phosphate backbone, sodium counterions and solvent we suggest that these are more realistic models than previous work using similar methods. However, a trimer of DNA brings us close to the size limit for application of DFT with the computing resources available to us. We therefore test and employ hybrid QM/MM methods for larger systems, in which the central bases are treated with dispersion-corrected DFT, while outer bases, sugar-phosphate backbone and solvent (where appropriate) with a molecular mechanics approach, thus allowing accurate and efficient description of systems consisting of hundreds of atoms.

\section{Computational methodology}

The initial structures of model systems were built in the canonical B-DNA geometry, using the w3DNA server ${ }^{20}$. Hydrogen atoms were added to the system according to expected protonation states at physiological $\mathrm{pH}$ using the Molecular Operating Environment (MOE) software package, and $\mathrm{Na}^{+}$were added manually in the vicinity of each phosphate group to produce an overall neutral structure. Where relevant, the central cytosine was also manually modified, and the results of all simulations were analysed using the X3DNA software package ${ }^{21,22}$. Atomic coordinates of wild-type, methylated and hydroxymethylated DNA dodecamers were obtained from X-ray structures deposited in the Protein Data Bank (PDB IDs: 1BNA, 4GJU, 4GLG, 4GLH and 4GLC) ${ }^{23}$, and truncated to 5'-ATTCGCG-3' heptamers containing a single modification on the central C. All DNA termini were capped with methyl groups for simplicity.

All DFT calculations were performed with the Gaussian09 simulation package ${ }^{20}$, using Grimme's B97-D functional ${ }^{24}$, that includes an explicit correction for the missing dispersion term in conventional DFT functionals, with either def2-TZVP or $6-31+G(d, p)$ basis set. This was previously recommended after thorough benchmarking 
for thermochemistry, kinetics, and non-covalent interactions ${ }^{25}$. All such calculations took advantage of the density fitting approximation, and where appropriate included the effect of aqueous solvation via the use of the polarized continuum model (PCM ${ }^{26}$. Binding energies are corrected for the effects of basis set superposition error using the counterpoise method ${ }^{27}$.

Hybrid QM/MM calculations were performed using the ONIOM approach with electrostatic embedding ${ }^{28}$, as implemented in Gaussian09. The boundary between the quantum and classical regions was chosen as the $\mathrm{N}-\mathrm{C} 1$ ' glycosidic bond in the relevant nucleotide. The QM regions were saturated by the use of a "link" hydrogen atom placed along the $\mathrm{N}-\mathrm{C} 1$ ' vector at an idealized distance, and were modelled at the B97-D/6-31+G(d,p) level of theory, again within PCM water. The MM part of these calculations employed the AMBER force field parm $96^{29}$, as defined within Gaussian09. The subtractive nature of the ONIOM method means that undefined terms in the MM expression do not contribute to the overall energy if the relevant atoms are entirely within the QM region, making it ideally suited for the purposes of the current study. We note that this approach has been widely adopted for $\mathrm{QM} / \mathrm{MM}$ studies of DNA and related structures ${ }^{30-32}$. Pure molecular mechanics (MM) geometry optimisation was also performed using the GROMACS simulation package ${ }^{33}$ and the AMBERParmbsc0 force field ${ }^{34}$, including RESP charges derived for modified bases in our previous work ${ }^{19}$, in explicit aqueous phase, specifically TIP3P water ${ }^{35}$ with $\mathrm{Na}^{+}$and $\mathrm{Cl}^{-}$counter ions to create a neutral system.

\section{Results and discussion}

\section{Gas-phase base pairs}

To examine the effect of modifications on base pairing we examined the structure and energy of gas-phase CG pairs in both hydrogen bonded and stacked orientations, with results reported in Table 1 and Table 2 respectively. These data show that methylation has little effect on the geometry or stability of the Watson-Crick base pair. The presence of a hydroxymethyl slightly weakens the $\mathrm{N}_{4}-\mathrm{H}_{4} \ldots \mathrm{O}_{6}$ $\mathrm{H}$-bond, perhaps due to the proximity of $\mathrm{CH}_{2} \mathrm{OH}$ and $\mathrm{NH}_{2}$ groups, reported as $\mathrm{X}_{\ldots} . \mathrm{H}_{4}$ in Table 1. Formyl has a larger effect overall, lengthening $\mathrm{N}_{3} \ldots \mathrm{H}_{1}-\mathrm{N}_{1}$ and $\mathrm{O}_{2} \ldots \mathrm{H}_{2}-\mathrm{N}_{2} \mathrm{H}$-bonds and hence reducing binding by over $3 \mathrm{kcal} / \mathrm{mol}$. The pattern of changes induced by carboxylate is different from all other modifications, lengthening the peripheral $\mathrm{H}$-bonds $\mathrm{N}_{4}-\mathrm{H}_{4} \ldots \mathrm{O}_{6}$ and $\mathrm{O}_{2} \ldots \mathrm{H}_{2}-\mathrm{N}_{2}$ markedly, but shortening $\mathrm{N}_{3} \ldots \mathrm{H}_{1}-\mathrm{N}_{1}$. Despite this weakening, the carboxylatesubstituted cytosine binds most strongly to guanine, presumably due to ion-dipole interactions within the anionic system. Both formyl and carboxylate contain close $\mathrm{O}_{\mathrm{N}} \mathrm{H}_{4}$ contacts, but overall the proximity of these groups does not appear to be related to strength or geometry of binding.

As well as the effect on H-bonding, epigenetic modifications can alter the stacking behaviour of DNA bases. Table 2 reports geometrical details, as well as binding energies, of the five modified cytosines considered here stacked with guanine. All such calculations started from the idealised B-DNA orientation $($ Cent... Cent $=$ $4.390 \AA$, Dihedral $=4.9^{\circ}$ ), and overall this is retained in our gasphase DFT optimisation. Table 2 shows that methylation leads to closer contact and greater stabilisation between bases, as might be
Table 1. Hydrogen bond lengths and binding energies of CG Watson-Crick base pairs from B97-D/def2-TZVP ( $\AA$ and kcal/mol).

\begin{tabular}{|l|c|c|c|c|c|}
\hline & $\mathbf{N}_{\mathbf{4}}-\mathbf{H}_{\mathbf{4}} \ldots \mathbf{O}_{\mathbf{6}}$ & $\mathbf{N}_{\mathbf{3}} \ldots \mathbf{H}_{\mathbf{1}}-\mathbf{N}_{\mathbf{1}}$ & $\mathbf{O}_{\mathbf{2}} \ldots \mathbf{H}_{\mathbf{2}}-\mathbf{N}_{\mathbf{2}}$ & $\mathbf{X} \ldots \mathbf{H}_{\mathbf{4}}{ }^{a}$ & $\begin{array}{l}\text { Binding } \\
\text { Energy }\end{array}$ \\
\hline C & 1.663 & 1.819 & 1.835 & 2.455 & -31.19 \\
\hline 5-mC & 1.660 & 1.817 & 1.822 & 2.375 & -31.70 \\
\hline 5-hC & 1.689 & 1.822 & 1.835 & 2.145 & -28.63 \\
\hline 5-fC & 1.670 & 1.834 & 1.884 & 1.990 & -28.07 \\
\hline 5-caC & 1.698 & 1.778 & 1.874 & 1.674 & -34.62 \\
\hline
\end{tabular}

a $\mathrm{X}$ refers to the atom of the substituent on position 5 closest to $\mathrm{H}_{4}$

\section{Table 2. Geometry and binding energies of stacked CG base pairs from B97-D/ def2-TZVP $\left(\AA .{ }^{\circ}\right.$ and $\left.\mathrm{kcal} / \mathrm{mol}\right)$.}

\begin{tabular}{|l|c|c|c|}
\hline & $\begin{array}{l}\text { Cent... } \\
\text { Cent }^{a}\end{array}$ & Dihedral & \\
\hline
\end{tabular}

expected due to the increased polarizability of this modified base. Hydroxymethylation leads to the most stable pair considered here, largely due to a strong $\mathrm{H}$-bond between the $\mathrm{H}-\mathrm{O}$ of hydroxymethyl and $\mathrm{O} 6$ of guanine $(\mathrm{H} . . \mathrm{O}=1.770 \AA)$, whereas formylation leads to longer, weaker interaction between bases. Carboxylatesubstituted cytosine is the only case considered here that loses the approximately parallel orientation of bases. This appears to be driven as much by repulsion between the carboxylate group and $\mathrm{C}=\mathrm{O}_{6}$ of guanine as by $\mathrm{H}$-bonding.

\section{Double-stranded DNA trimers}

While these gas-phase dimers give useful information on the intrinsic effect of modifications on cytosine's ability to interact with guanine, environmental effects including the DNA sequence, sugar-phosphate backbone and solvent will play a major role in determining their effect in real systems. In order to better simulate the behaviour of modified cytosines in real systems, structures of double-stranded d(GCG) and d(ACA), as well as epigenetic modifications to the central cytosine were optimized using DFT in continuum solvent (PCM), and the resulting geometries of the local base pairs were analysed in the coordinate frame recommended by Olson et al $^{36}$. Unlike the free dimers considered above, modifications have only subtle effects on this larger structure, which retains the overall canonical B-DNA shape of the unmodified WT structure. 
Following Zubatiuk et al. ${ }^{37}$, we summarise key aspects of trimer structure, which are displayed graphically in Figure 2 and Figure 3. The corresponding values are tabulated in Table S1 of the Supporting Information, with the base step and local helical parameters tabulated in Table S2. As with Zubatiuk et al..$^{14}$, base pair step parameters are averaged over 3' and 5' directions. In the GCG oligomer, methylation has only a small effect on base pair distances, but does alter the propeller angle by over $4^{\circ}$. Hydroxymethylation has a larger effect on the GCG oligomer, especially on the stagger, buckle and propeller, whereas the stretch and opening parameters are much less affected. Formyl does not strongly affect base pair distances but does change angles substantially, especially buckle and propeller, which change by as much as $10^{\circ}$. In contrast, carboxylate induces a large change in stagger but only small changes in angular geometry. Base pair step parameters for $\mathrm{d}(\mathrm{GCG})$ in general are less affected than those for the base pair noted above, with the exception of formyl which exhibits smaller slide and less negative roll values than unmodified DNA.
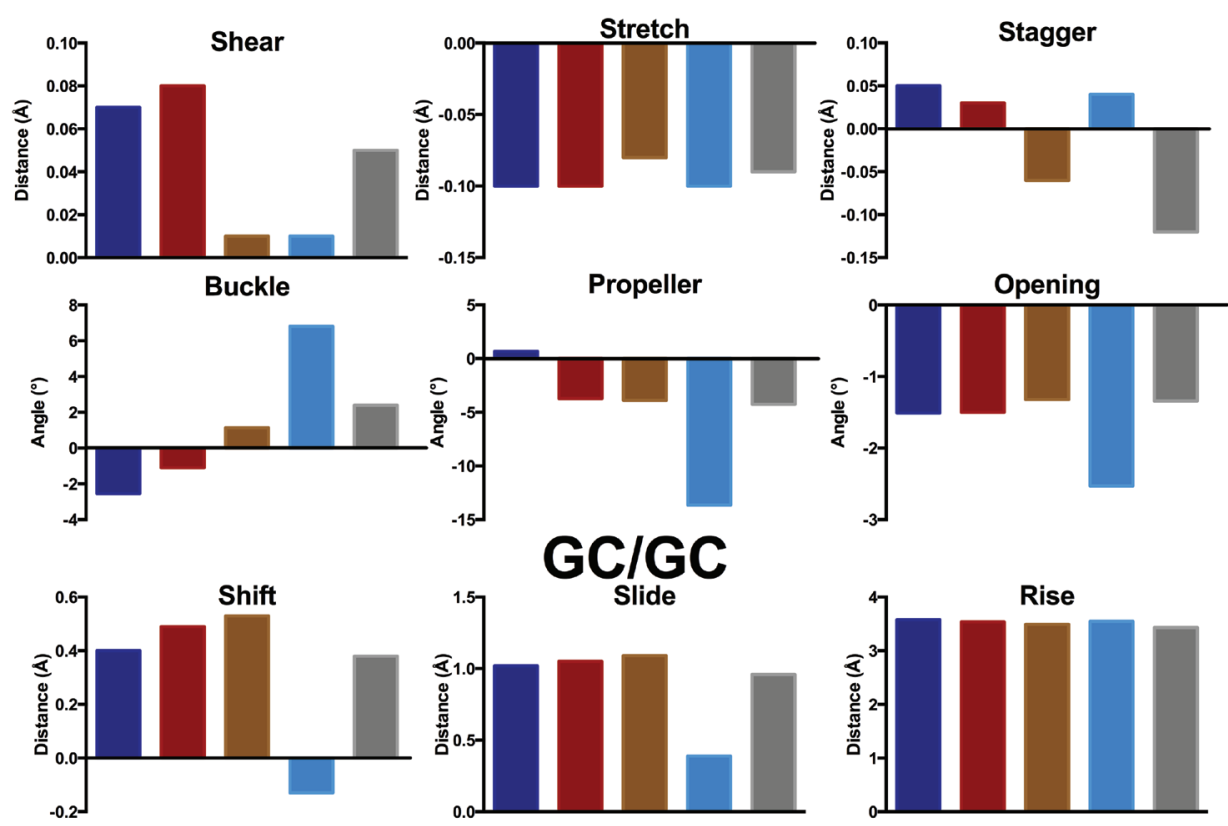

GC/GC
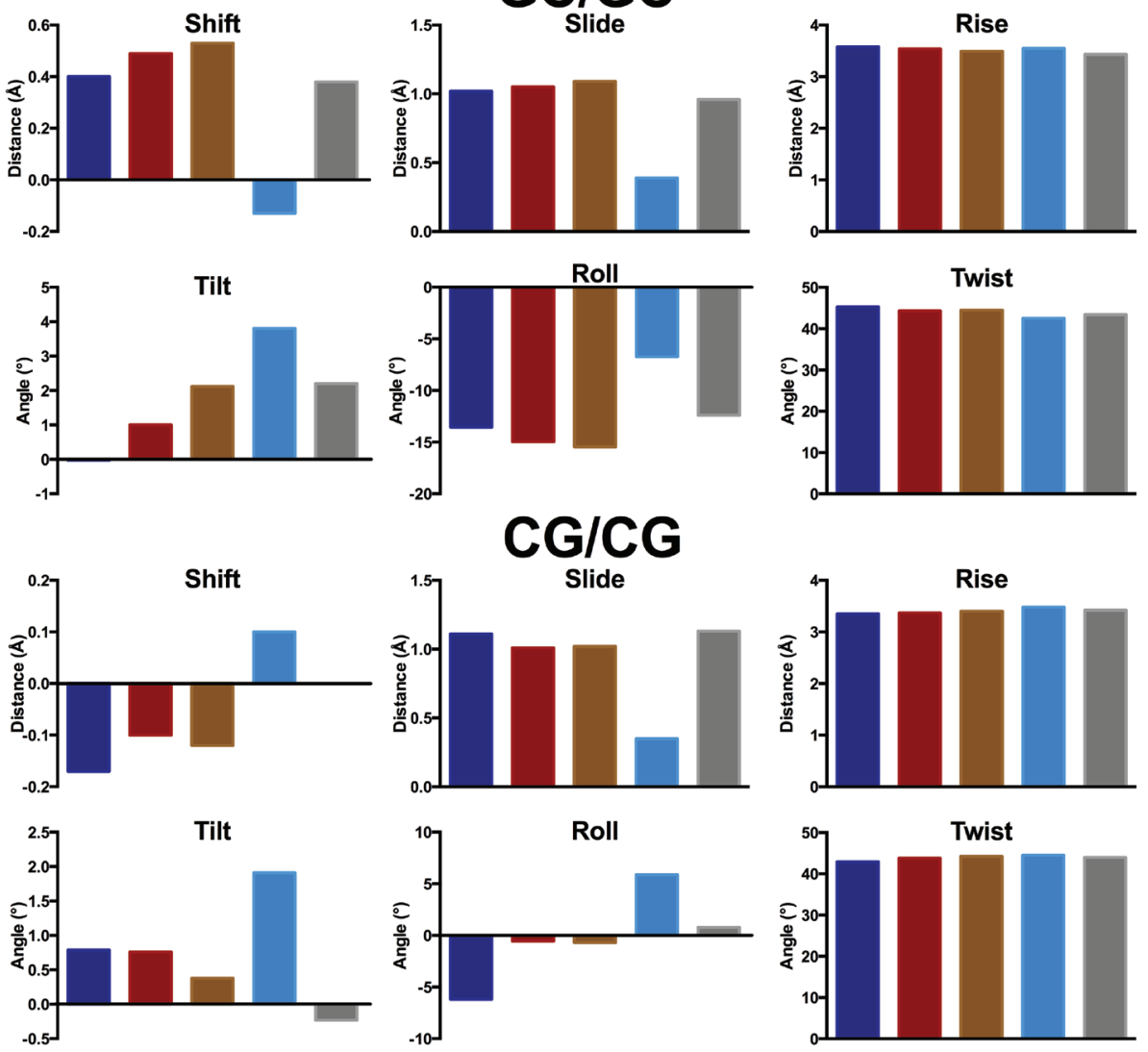

Native

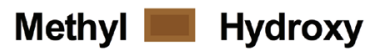

Formyl

Carboxy

Figure 2. Base pair (A) and step (B, C) parameters for central GC in d(GCG) and modifications ( $\AA^{\circ}$ and $\left.{ }^{\circ}\right)$. The corresponding data are provided in Table S1. 
Rather larger changes are evident on modification of d(ACA), as shown in Figure 3. In this case, even methylation induces significant changes in distances, especially stagger which increases by $0.1 \AA$, and angles (buckle and propeller change by 8 and $13^{\circ}$, respectively). At the base pair step level, methylation gives rise to substantial increase $(0.9$ and $1.5 \AA)$ in slide and more negative roll in both $3^{\prime}$ and $5^{\prime}$ directions. Less apparent in Figure 3, but still notable, are changes in rise that are 0.1 and $0.3 \AA$ smaller in the methylated structure, reflecting the greater stacking that results from addition of a methyl group. Other modifications induce different patterns of structural change: for the central base pair these changes are typically smaller than for methylation, but for base pair steps much larger changes are found in some parameters. Most notable of these are slide, which changes by over $3 \AA$ and roll (up to $17^{\circ}$ ) in the $3^{\prime}$ direction, in a similar way to that reported previously for smaller systems ${ }^{17,18}$. Other parameters such as the width of the DNA strand,
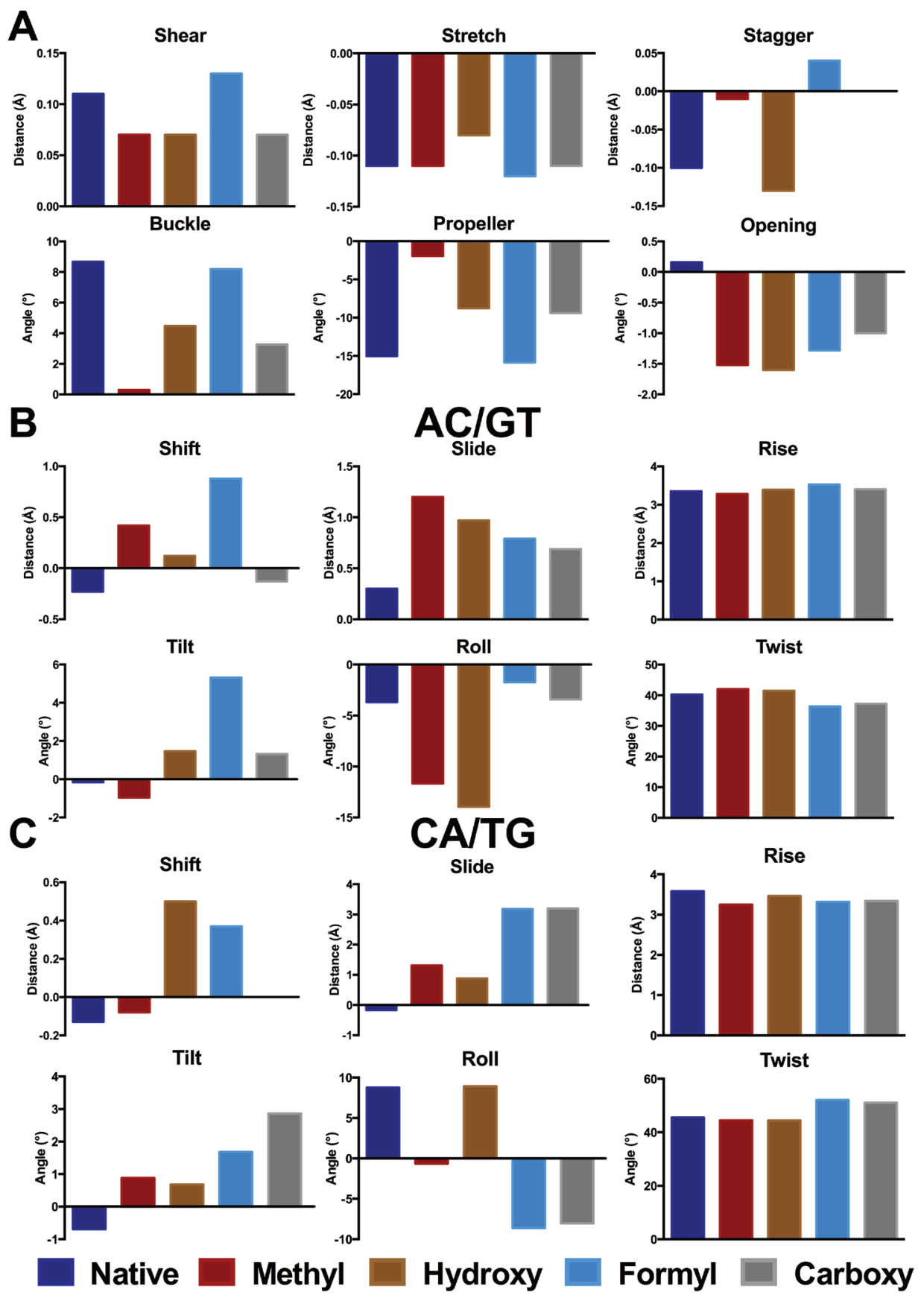

Figure 3. Base pair (A) and step (B, C) parameters for central GC in d(ACA) and modifications $\left(\AA \AA^{\circ}\right.$ and $\left.{ }^{\circ}\right)$. The corresponding data are provided in Table S1. 
measured as the distance between $\mathrm{C}^{\prime}{ }^{\prime}$ nuclei, and virtual angles $\lambda_{\mathrm{Y}}$ and $\lambda_{\mathrm{R}}$, which describe the pivoting of complementary bases in the base-pair plane, vary only slightly from the idealised values for B-DNA.

\section{QM/MM studies of double-stranded oligomers}

The oligomers considered so far are close to the limit of our computational capabilities of current DFT methods (the largest structure, carboxylated d(ACA), has 962 electrons in 2743 basis functions), such that longer sequences cannot currently be routinely studied in this manner. However, they are too small to correctly represent how DNA behaves in a real system, where the conformations adopted by each base pair step depend on the neighbouring step. Moreover, simulations of nucleic acids are known to suffer problems due to greater elasticity of the terminal part of the structure (the so called "end-effect" ${ }^{38}$ ). For these reasons, these small oligomers are inadequate models to probe the effects of epigenetic modifications on the structure of DNA. We therefore turn to hybrid QM/MM methods, in which a subset of the atoms in the system is treated with DFT, and the remainder of the system with much faster molecular mechanics methods. In order to test the validity of this approach, methylated GCG was optimized using either only two or six bases in the QM region (Figure 4). These tests show that including only two bases in the QM region leads to significant differences in geometry to that obtained from DFT, particularly in the stagger and buckle coordinates. In contrast, including six bases in the QM region reproduces the DFT structure reasonably well. Similar observations were made from analogous treatment of methylated ACA (data not shown).

As a further test, we also compared DFT and QM/MM derived structures with those optimised using the force field parameters developed in our previous work. Figure 5 shows the base-pair parameter values of the methylated structure $d\left(\mathrm{GC}^{\prime} \mathrm{G}\right)$ for the different methods. The MM structures provide very close values to those obtained by both QM/MM and DFT approaches, showing slight difference only in the stagger and propeller angle. We can therefore conclude that for small DNA oligomers, DFT, QM/MM and MM methods can all produce almost equally adequate DNA structures, but that $\mathrm{QM} / \mathrm{MM}$ and $\mathrm{MM}$ approaches are more similar to one another than those obtained from DFT alone.

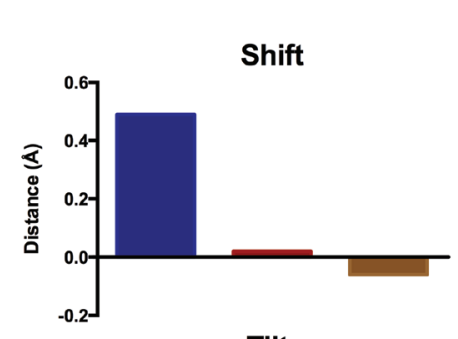

Tilt
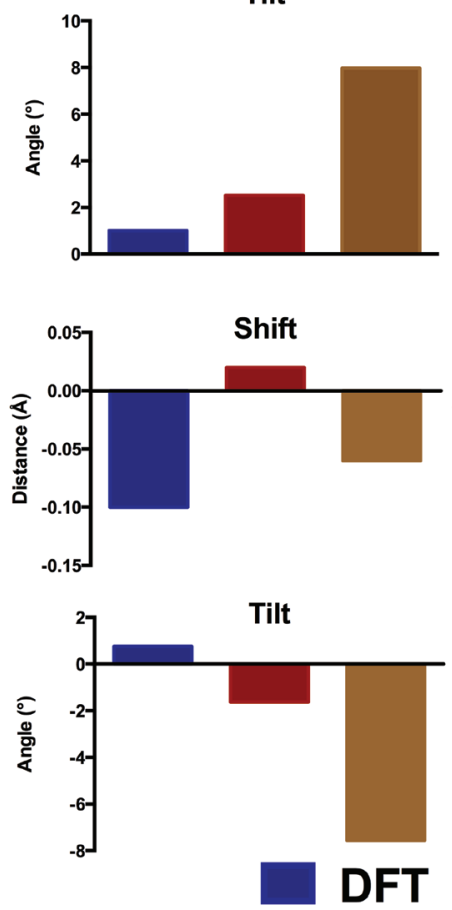

\section{GC'/CG}

Slide

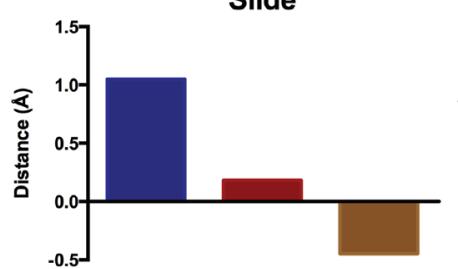

Roll

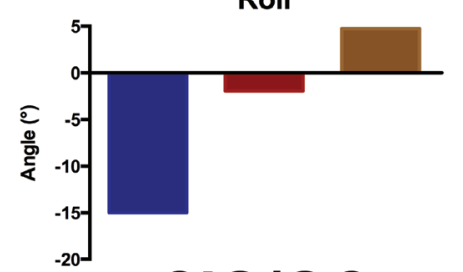

C'G/GC

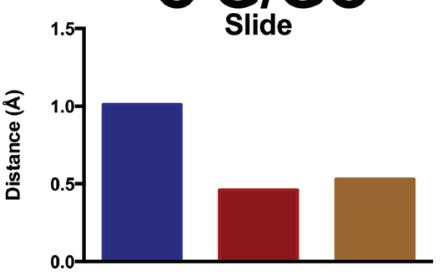

Roll

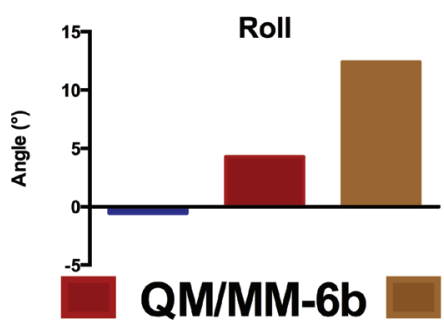

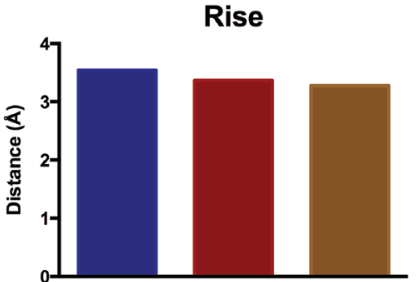

Twist
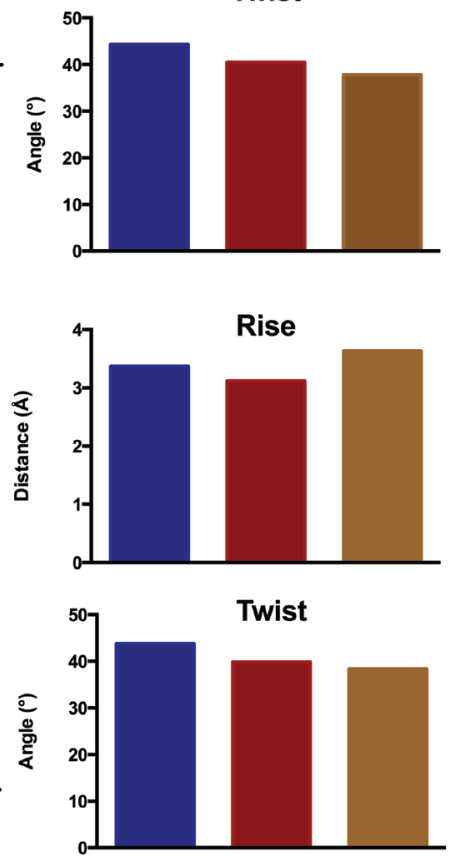

Figure 4. Comparison of QM/MM with DFT geometry (Å and ${ }^{\circ}$ ). The corresponding values are shown in Tables S3 and S4. 

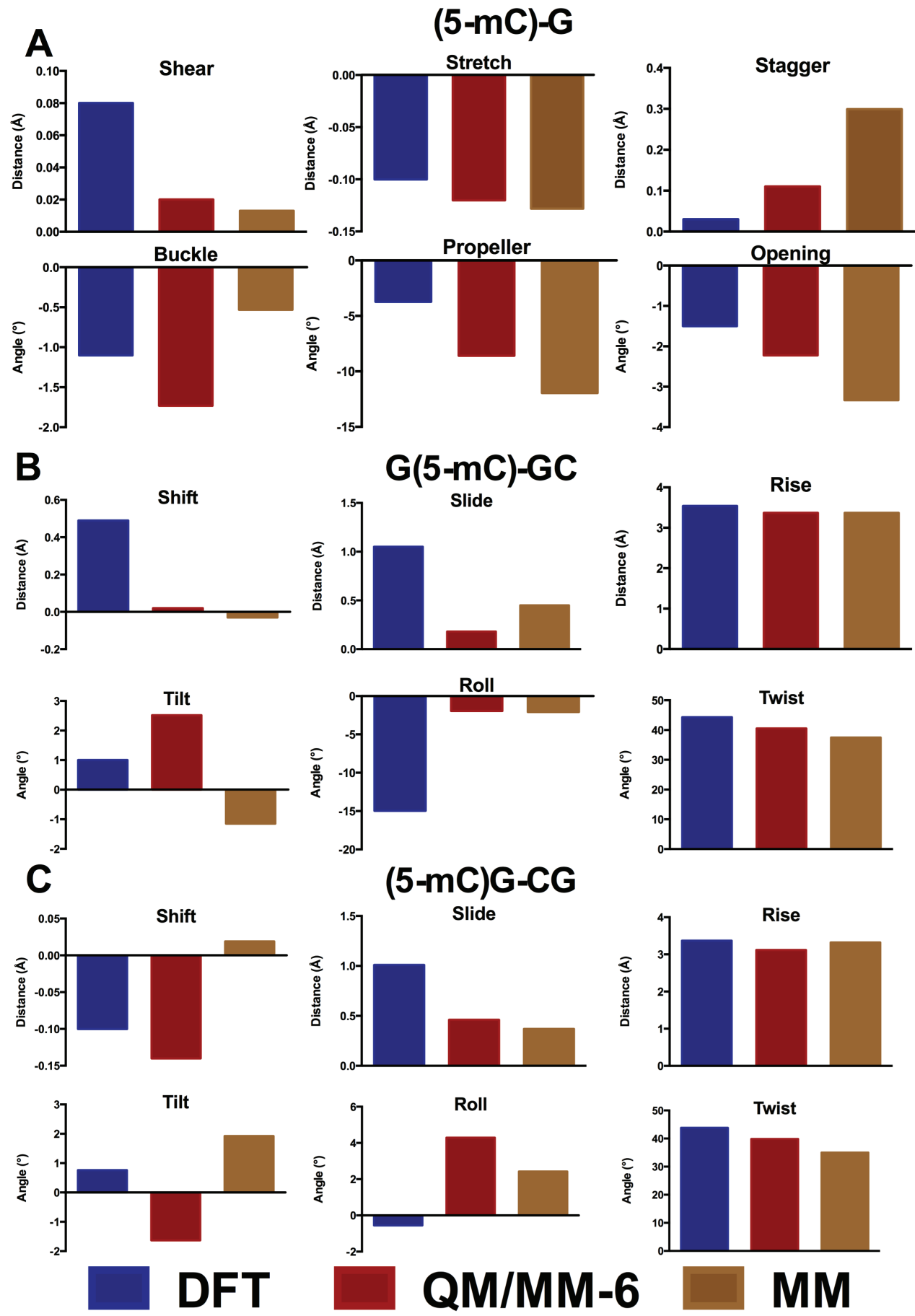

Figure 5. Comparison of DFT, QM/MM and molecular mechanics energy minimised (EM) geometries of $\mathrm{d}^{\mathrm{G}}\left(\mathrm{GC} \mathrm{C}^{\prime} \mathrm{G}\right)\left(\AA^{\circ}\right.$ and $\left.{ }^{\circ}\right)$. The corresponding values are shown in Tables S3 to S6.

QM/MM geometry optimization with six bases in the QM region was then applied to a set of larger DNA sequences. The experimental structure of Renčiuk et al. ${ }^{4}$ obtained using X-ray diffraction (PDB Entry 4GLG) was truncated to a sequence of 7 base pairs, i.e. 5'-ATT CGCG-3', and the central 6 bases (TCG//CGA) assigned as QM atoms. The remaining atoms, including crystallographic water molecules and counterions, were assigned to the MM layer, and the entire system was geometry optimized. The resulting optimized structure of the system with methylated $\mathrm{C}$ in the central position is shown in Figure 6. Base pair and base pair step geometries of wild type, methylated, hydroxymethylated structures optimised with QM/MM, along with experimental values for methylated C, are shown in Figure 7. 


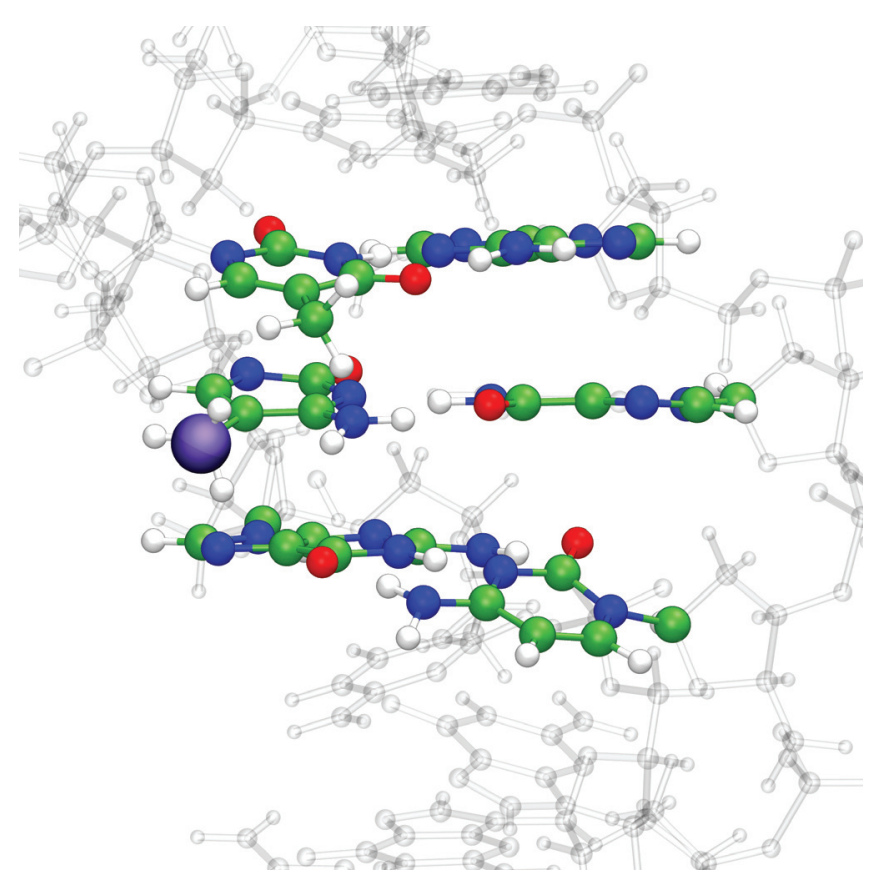

Figure 6. QM/MM optimised structure of 5'-ATTCGCG-3' with 5-mC in central position, and the bases defined as QM atoms shown in CPK. A purple sphere highlights the methylation position, and water molecules and counterions have been omitted for clarity.

We find that the structural effect of methylation is larger in this longer sequence than in the trimers considered above. Particularly, the optimized values of shear, stagger and buckle of the central base pair differ markedly between the methylated and WT forms of DNA. In contrast, the base pair step parameters exhibit rather smaller changes. For the hydroxymethylated structures, we observe similar profiles to the methylated structures. Furthermore, our simulations also allow us to probe the preferred orientation of the hydroxymethyl group: our DFT calculations predict a slight preference for the $\mathrm{OH}$ group to point in $3^{\prime}$ over $5^{\prime}$ and an optimized of C6-C5-C5A-O5 torsion angle of $118.4^{\circ}$, while previous MD simulations show this torsion to vary between 85 and $120^{\circ}$ over $100 \mathrm{~ns}$ of simulation $^{19}$. This is in good agreement with the experimental and theoretical results of Renčiuk et al. ${ }^{39}$, who reported values between 72 and $133^{\circ}$ using X-ray diffraction methods.

\section{Data of theoretical modelling of epigenetically modified DNA sequences}

3 Data Files

http://dx.doi.org/10.6084/m9.figshare.1310448

\section{Conclusions}

Through use of modern, dispersion-corrected DFT and hybrid QM/MM methods, we have examined the structural consequences of epigenetic modifications of DNA. Concentrating on methylation and related modifications of cytosine, we show that the overall Watson-Crick base-pairing is retained, with rather small changes to hydrogen bond and stacking geometries. Despite this, some modifications have a substantial effect on the strength of intermolecular interactions: hydroxymethyl and formyl groups reduce H-bonding strength, while carboxylate increases this markedly.

Situating these modifications within the double-stranded DNA trimers GCG and ACA allows us to examine the effects on the central CG base pair and base pair steps. Base pair geometries undergo rather larger changes within ACA than in GCG, with changes in buckle and propeller angles particularly apparent. Changes to base pair steps are smaller, although some changes in shift and slide values due to modifications are evident. Optimised geometries also act as a useful test of hybrid QM/MM methods. These can reproduce DFT structures if all six bases are included in the QM region, but if only the central base pair is treated with QM significant differences result. This approach is then applied to heptamers derived from a recent X-ray crystallography; here again, the central base pair is found to be significantly disrupted, whereas base pair step parameters are largely retained.

The studies reported here deal solely with static structures, but it is well-known that DNA is a flexible system that is in constant motion at biologically relevant temperatures. In previous work, we showed that long timescale molecular dynamics was able to highlight subtle differences in structure, flexibility and solvation resulting from incorporation of 5-mC and 5-hC in several different DNA sequences. The work reported here gives new insight into the intrinsic effects of epigenetic modification of cytosine, complementing our previous molecular dynamics study ${ }^{19}$ as well as providing support for the molecular mechanics force field chosen for that work. 

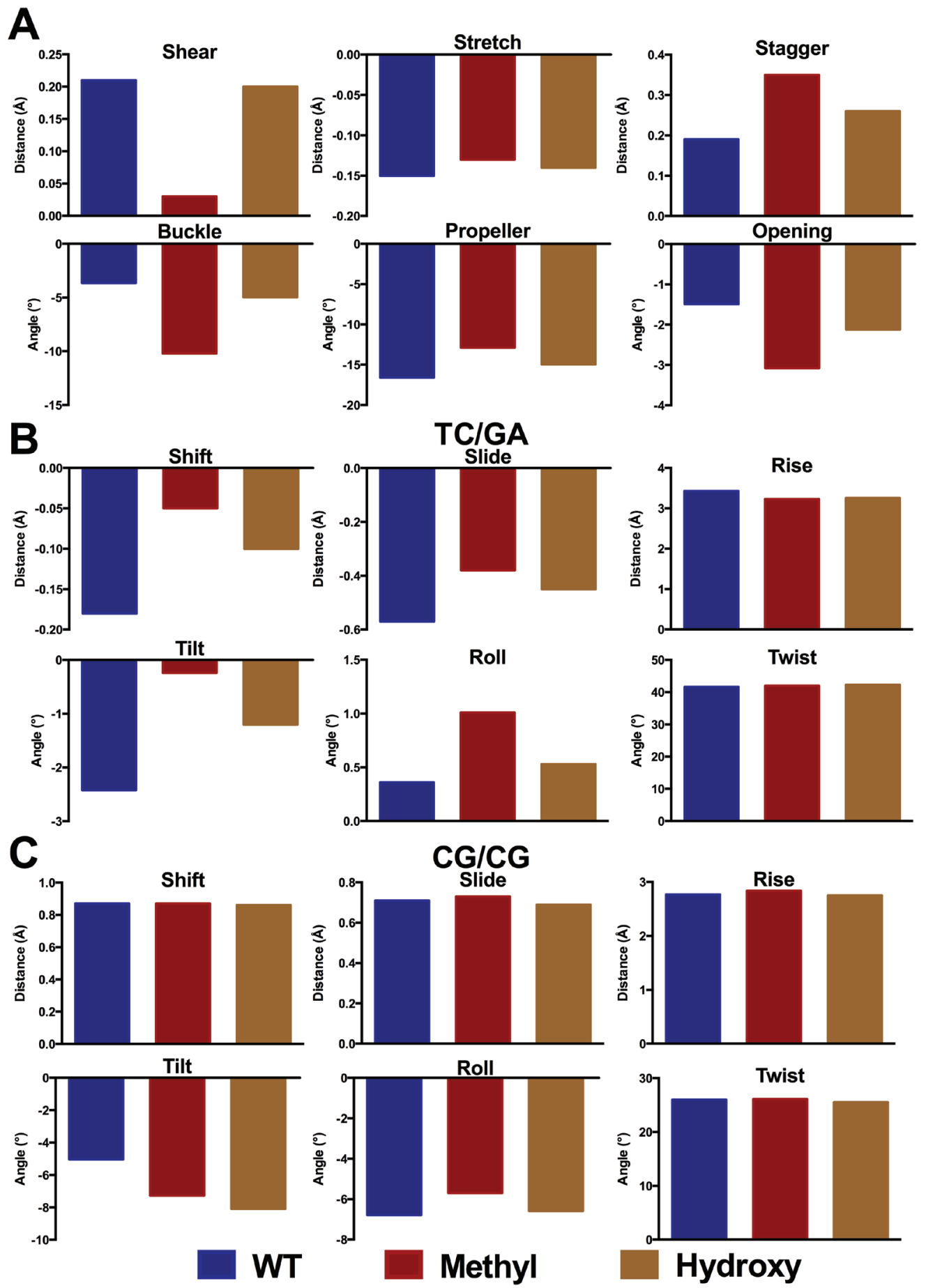

Figure 7. Base pair step parameters for central GC in $5^{\prime}$-ATTCGCG-3' and modifications ( $\left(\AA^{\prime}\right.$ and ${ }^{\circ}$ ). The corresponding values are shown in Table S2. 
Data availability

Figshare: Data of theoretical modelling of epigenetically modified DNA sequences. Doi: 10.6084/m9.figshare.1310448 ${ }^{40}$

\section{Author contributions}

SKTSW, JP and SCLK conceived the study. AC, JP and SCLK designed the research. AC, LG and CRK contributed to design of the research. JP carried out the research. JP and SCLK prepared the first draft of the manuscript. All authors analysed data and contributed to preparation of the manuscript. All authors were involved in the revision of the draft manuscript, and have agreed to the final content.

\section{Competing interests}

No competing interests were disclosed.

\section{Grant information}

This work was supported by the Swedish Research Council (Vetenskapsrådet, 2010-5026) and funding from the Sven and Ebba Christina Hagbergs Foundation.

We confirm that the funders had no role in study design, data collection and analysis, decision to publish, or preparation of the manuscript.

\section{Acknowledgements}

JAP is grateful to Advanced Research Computing @ Cardiff (ARCCA) for use of computing facilities.
1. Korlach J, Turner SW: Going beyond five bases in DNA sequencing. Curr Opin Struc Biol. 2012; 22(3): 251-61.

PubMed Abstract | Publisher Full Text

2. Colot V, Rossignol JL: Eukaryotic DNA methylation as an evolutionary device. Bioessays. 1999; 21(5): 402-11.

PubMed Abstract

3. Ito $\mathrm{S}$, Shen $\mathrm{L}$, Dai $\mathrm{Q}$, et al:: Tet proteins can convert 5-methylcytosine to 5-formylcytosine and 5-carboxylcytosine. Science. 2011; 333(6047): $1300-3$.

PubMed Abstract | Publisher Full Text | Free Full Text

4. Renčiuk D, Blacque O, Vorlickova M, et al.: Crystal structures of B-DNA dodecamer containing the epigenetic modifications 5-hydroxymethylcytosine or 5-methylcytosine. Nucleic Acids Res. 2013; 41(21): 9891-900. PubMed Abstract | Publisher Full Text | Free Full Text

5. Barone G, Guerra CF, Bickelhaupt FM: B-DNA structure and stability as function of nucleic acid composition: Dispersion-corrected DFT study of dinucleoside monophosphate single and double strands. ChemistryOpen. 2013; 2(5-6): 186-193.

PubMed Abstract | Publisher Full Text | Free Full Text

6. van der Wijst T, Guerra CF, Swart M, et al:: Performance of various density functionals for the hydrogen bonds in DNA base pairs. Chem Phys Lett. 2006; 426(4-6): 415-421.

Publisher Full Tex

7. Poater J, Swart M, Guerra CF, et al:: Solvent effects on hydrogen bonds in Watson-Crick, mismatched, and modified DNA base pairs. Comp Theoret Chem. 2012; 998: 57-63.

Publisher Full Text

8. Mládek A, Šponer JE, Jurečka $P$, et al: Conformational energies of DNA sugarphosphate backbone: Reference QM calculations and a comparison with density functional theory and molecular mechanics. $J$ Chem Theory Comput. 2010; 6(12): 3817-3835.

Publisher Full Text

9. Svozil D, Hobza $P$, Šponer J: Comparison of intrinsic stacking energies of ten unique dinucleotide steps in A-RNA and B-DNA duplexes. Can we determine correct order of stability by quantum-chemical calculations? J Phys Chem B. 2009; 114(2): 1191-1203.

Publisher Full Text

10. Banáš $P$, Mládek $A$, Otyepka $M$, et al.: Can we accurately describe the structure of adenine tracts in B-DNA? Reference quantum-chemical computations reveal overstabilization of stacking by molecular mechanics. $J$ Chem Theory Comput. 2012; 8(7): 2448-2460.

Publisher Full Text

11. Fonville JM, Swart M, Vokacova Z, et al.: Chemical shifts in nucleic acids studied by density functional theory calculations and comparison with experiment. Chemistry. 2012; 18(39): 12372-87.

PubMed Abstract | Publisher Full Text

12. Mládek A, Šponer JE, Kulhánek $P$, et al:: Understanding the sequence preference of recurrent RNA building blocks using quantum chemistry: The intrastrand RNA dinucleotide platform. J Chem Theory Comput. 2011; 8(1): 335-347.

PubMed Abstract | Publisher Full Text | Free Full Text
13. Morgado CA, Svozil D, Turner DH, et al:: Understanding the role of base stacking in nucleic acids. MD and QM analysis of tandem GA base pairs in RNA duplexes. Phys Chem Chem Phys. 2012; 14(36): 12580-91. PubMed Abstract | Publisher Full Text

14. Zubatiuk TA, Shishkin OV, Gorb L, et al.: B-DNA characteristics are preserved in double stranded $d(A) 3 \cdot d(T) 3$ and $d(G) 3 \cdot d(C) 3$ mini-helixes: conclusions from DFT/M06-2X study. Phys Chem Chem Phys. 2013; 15(41): 18155-66. PubMed Abstract | Publisher Full Text

15. Gu J, Wang J, Xie Y, et al.: Structural and electronic property responses to the arsenic/phosphorus exchange in GC-related DNA of the B-form. $J$ Comput Chem. 2012; 33(8): 817-21.

PubMed Abstract | Publisher Full Text

16. Gu J, Wang J, Leszczynski J: Stacking and H-bonding patterns of dGpdC and dGpdCpdG: Performance of the M05-2X and M06-2X Minnesota density functionals for the single strand DNA. Chem Phys Lett. 2011; 512(1-3): 108-112. Publisher Full Text

17. Acosta-Silva C, Branchadell V, Bertran J, et al:: Mutual relationship between stacking and hydrogen bonding in DNA. Theoretical study of guaninecytosine, guanine-5-methylcytosine, and their dimers. J Phys Chem B. 2010; 114(31): 10217-27.

PubMed Abstract | Publisher Full Text

18. Yusufaly TI, Li Y, Olson WK: 5-Methylation of cytosine in CG:CG base-pair steps: a physicochemical mechanism for the epigenetic control of DNA nanomechanics. J Phys Chem B. 2013; 117(51): 16436-42. PubMed Abstract | Publisher Full Text | Free Full Text

19. Carvalho AT, Gouveia L, Kanna CR, et al.: Understanding the structural and dynamic consequences of DNA epigenetic modifications: Computational insights into cytosine methylation and hydroxymethylation. Epigenetics. 2014; 9(12): 1604-12.

PubMed Abstract | Publisher Full Text

20. Frisch MJ, Trucks GW, Schlegel HB, et al.: Gaussian Rev. C.01, Gaussian, Inc.: Wallingford, CT, USA, 2009.

21. Lu XJ, Olson WK: 3DNA: A software package for the analysis, rebuilding and visualization of three-dimensional nucleic acid structures. Nucleic Acids Res. 2003; 31(17): 5108-21.

PubMed Abstract | Publisher Full Text | Free Full Text

22. Lu XJ, Olson WK: 3DNA: a versatile, integrated software system for the analysis, rebuilding and visualization of three-dimensional nucleic-acid structures. Nat Protoc. 2008; 3(7): 1213-27.

PubMed Abstract | Publisher Full Text | Free Full Text

23. Drew HR, Wing RM, Takano T, et al.: Structure of a B-DNA dodecamer: conformation and dynamics. Proc Natl Acad Sci U S A. 1981; 78(4): 2179-2183. PubMed Abstract | Publisher Full Text | Free Full Text

24. Grimme S: Semiempirical GGA-type density functional constructed with a long-range dispersion correction. J Comput Chem. 2006; 27(15): 1787-99. PubMed Abstract | Publisher Full Text

25. Goerigk L, Grimme S: A thorough benchmark of density functional methods for general main group thermochemistry, kinetics, and noncovalent interactions. Phys Chem Chem Phys. 2011; 13(14): 6670-88.

PubMed Abstract | Publisher Full Text

26. Miertuš S, Scrocco E, Tomasi J: Electrostatic interaction of a solute with 
a continuum. A direct utilization of $A B$ initio molecular potentials for the prevision of solvent effects. Chemical Physics. 1981; 55(1): 117-129. Publisher Full Text

27. Boys SF, Bernardi F: The calculation of small molecular interactions by the differences of separate total energies. Some procedures with reduced errors. Mol Phys. 1970; 19(4): 553-566.

Publisher Full Text

28. Bakowies D, Thiel W: Hybrid models for combined quantum mechanical and molecular mechanical approaches. J Phys Chem. 1996; 100 (25): 10580-10594. Publishser Full Text

29. Cornell WD, Cieplak $\mathrm{P}$, Bayly $\mathrm{Cl}$, et al.: A second generation force field for the simulation of proteins, nucleic acids, and organic molecules. J Am Chem Soc. 1995; 117(19): 5179-5197.

Publisher Full Text

30. Cerón-Carrasco JP, Requena A, Jacquemin D: Impact of DFT functionals on the predicted magnesium-DNA interaction: an ONIOM study. Theor Chem AcC. 2012; 131: 1188

Publisher Full Text

31. Sundaresan N, Pillai CK, Suresh $\mathrm{CH}$ : Role of $\mathbf{M g}^{2+}$ and $\mathrm{Ca}^{2+}$ in DNA bending: Evidence from an ONIOM-based QM-MM study of a DNA fragment. J Phys Chem A. 2006; 110(28): 8826-31.
PubMed Abstract | Publisher Full Text

32. Ahmadi F, Jahangard-Yekta S, Heidari-Moghadam A, et al:: Application of two-layer ONIOM for studying the interaction of $\mathrm{N}$-substituted piperazinylfluoroquinolones with ds-DNA. Comp Theor Chem. 2013; 1006 : 9-18. Publisher Full Text

33. Pronk S, Páll S, Schulz R, et al.: GROMACS 4.5: A high-throughput and highly parallel open source molecular simulation toolkit. Bioinformatics. 2013; 29(7):
845-854.

PubMed Abstract | Publisher Full Text | Free Full Text

34. Pérez A, Marchán I, Svozil D, et al:: Refinement of the AMBER force field for nucleic acids: Improving the description of $\alpha / \gamma$ conformers. Biophys J. 2007; 92(11): 3817-3829.

PubMed Abstract | Publisher Full Text | Free Full Text

35. Jorgensen WL, Chandrasekhar J, Madura JD, et al.: Comparison of simple potential functions for simulating liquid water. J Chem Phys. 1983; 79(2): 926-935

Publisher Full Text

36. Olson WK, Bansal M, Burley SK, et al: A standard reference frame for the description of nucleic acid base-pair geometry. J Mol Biol. 2001; 313: 229-237. Publisher Full Text

37. Olson WK, Gorin AA, Lu XJ, et al:: DNA sequence-dependent deformability deduced from protein-DNA crystal complexes. Proc Natl Acad Sci U S A. 1998 95(19): 11163-8. PubMed Abstract | Publisher Full Text | Free Full Text

38. Dixit SB, Bevridge DL, Case DA, et al:: Molecular dynamics simulations of the 136 unique tetranucleotide sequences of DNA oligonucleotides. II: Sequence context effects on the dynamical structures of the 10 unique dinucleotide steps. Biophys J. 2005; 89(6): 3721-40. PubMed Abstract | Publisher Full Text | Free Full Text

39. Renčiuk D, Kejnovská I, Školáková P, et al:: Arrangements of human telomere DNA quadruplex in physiologically relevant $\mathrm{K}^{+}$solutions. Nucleic Acids Res. 2014; 37(19): 6625-6634. Publisher Full Text

40. Kamerlin SCL, Platts J, Carvalho ATP: Data of theoretical modelling of epigenetically modified DNA sequences. Figshare. 2014. Data Source 


\title{
Open Peer Review
}

\section{Current Peer Review Status:}

\section{Version 1}

Reviewer Report 17 April 2015

\section{https://doi.org/10.5256/f1000research.6589.r8191}

(C) 2015 Petzold K. This is an open access peer review report distributed under the terms of the Creative Commons Attribution License, which permits unrestricted use, distribution, and reproduction in any medium, provided the original work is properly cited.

\author{
Katja Petzold \\ Department of Medical Biochemistry and Biophysics (MBB-Molecular Structural Biology), \\ Karolinska Institute, Stockholm, Sweden
}

This paper presents a study of different simulation methods to investigate different modification of dCMp in base pairs or dsDNA and their influence of the surrounding structure.

1. Disparate statement in the abstract - please modify/clarify: "The same modifications within double-stranded GCG and ACA trimers exhibit rather larger structural effects" versus "but these leave the overall helical shape of DNA essentially intact." larger changes but DNA shape of helix intact?

2. Please clarify statement in introduction: "Fascinatingly, such modifications may be heritable despite not affecting DNA sequence, although the mechanism(s) by which this could be achieved are currently unknown." In respect to enzymes (e.g. DNA methyltransferase) known to transfer methylation from parent to daughter strands?

3. Please enhance figures for clarity.

A: Fig 1: numbering of atoms, full name of modifications, example GC WC base pair geometry and info on parameters "role, rise twist etc...".

B: Fig. 2-5 \& 7: please keep coherent direction of sequences e.g. GC/GC (5'-3'/5'-3') in Fig. 2 vs Fig. 4 GC/CG, or coherent naming of modification: Fig. 2 - no indication which nucleotide is modified, Fig. 4: $C^{\prime}$, Fig. 5: (5-mC), if mis-understood - please clarify.

C: Please give more detail in each of the Figure caption (e.g. construct, reference structure Fig. 7).

D: Fig. 7: what is the reference "along with experimental values for methylated C" - are the values shown here the X-ray structure values or the X-ray Structure values optimized with QM/MM for the WT? - if it is the optimized data, than I suggest to add the experimental data 
uncorrected as well.

4. It is difficult to estimate the significance of the changes in structural parameters between different cytosine modifications or different simulation methods, as there are no errors/standard deviations are presented. I would suggest using a set of X-ray/NMR structures with the same sequence and/or modifications to create a standard deviation for the different parameters to give the analysis more significance (than I can estimate if a difference of $0.03 \AA$ is of importance or not: "Formyl has a larger effect overall, lengthening $\mathrm{N} 3 . . . \mathrm{H} 1-\mathrm{N} 1$ and $\mathrm{O} 2 . . . \mathrm{H} 2-\mathrm{N} 2 \mathrm{H}$-bonds and hence reducing binding by over $3 \mathrm{kcal} / \mathrm{mol} . "$ Difference in h-bond length from wtC is $0.025 \AA$ and $0.049 \AA$, respectively - seems very small, but if all GC wc bp are within of $0.01 \AA$ distance, this would be significant).

Important for: Table $1 \& 2$ - as well important for Fig. 2-5 \& 7, please adjust.

5. Describe structural/distortion findings in structure/sketches. E.g.: "largely due to a strong $\mathrm{H}$ bond between the $\mathrm{H}-\mathrm{O}$ of hydroxymethyl and $\mathrm{O} 6$ of guanine $(\mathrm{H} . . . \mathrm{O}=1.770 \AA)$ " for a better understanding of how the structures are supposed to look like.

6. Formality: p5 first sentence "Following Zubatiuk et al.37," should be "Following Olson et al .37," OR “Following Zubatiuk et al.14,"

7. More information on the Methods and Materials would be appreciated: E.g. How extensive where the simulations/optimizations? What were the energy cutoffs?...

Competing Interests: No competing interests were disclosed.

I confirm that I have read this submission and believe that I have an appropriate level of expertise to confirm that it is of an acceptable scientific standard, however I have significant reservations, as outlined above.

Author Response ( F1000Research Advisory Board Member ) 23 Apr 2015

Lynn Kamerlin

We thank the referee for the time taken to review our manuscript. Please find a point-bypoint response below, with our responses italicised.

1. Disparate statement in the abstract - please modify/clarify: "The same modifications within double-stranded GCG and ACA trimers exhibit rather larger structural effects" versus "but these leave the overall helical shape of DNA essentially intact." larger changes but DNA shape of helix intact?

We do not see these statements as contradictory: we show that there are indeed substantial changes in $\mathrm{H}$-bonding and stacking interactions, but that these are not sufficient to disrupt the overall helical structure. We have, however, now explicitly included this in the abstract to prevent reader confusion.

2. Please clarify statement in introduction: "Fascinatingly, such modifications may be heritable despite not affecting DNA sequence, although the mechanism(s) by which 
this could be achieved are currently unknown." In respect to enzymes (e.g. DNA methyltransferase) known to transfer methylation from parent to daughter strands?

This is certainly one key mechanism, but this is not the place to discuss in detail the biology of epigenetics, which is covered at length in references cited. We have made this point more explicit in the introduction and refer the reader to reference 1 for further information about currently proposed mechanisms.

3. Please enhance figures for clarity.

The figures have been modified as outlined below and we hope the improved version is now clearer to the reader.

A: Fig 1: numbering of atoms, full name of modifications, example GC WC base pair geometry and info on parameters "role, rise twist etc...".

Numbering has been added to Figure 1, as has a representation of CG base pair. Roll, rise, twist etc. are widely used in DNA studies and should not need re-definition here.

B: Fig. 2-5 \& 7: please keep coherent direction of sequences e.g. GC/GC (5'-3'/5'-3') in Fig. 2 vs Fig. 4 GC/CG, or coherent naming of modification: Fig. 2 - no indication which nucleotide is modified, Fig. 4: $\mathrm{C}^{\prime}$, Fig. 5: (5-mC), if mis-understood - please clarify.

The legend for figures 2 to 4 has been altered to explain that central C has been modified.

C: Please give more detail in each of the Figure caption (e.g. construct, reference structure - Fig. 7).

Legend for Figure 7 has been expanded to clarify source of data.

D: Fig. 7: what is the reference "along with experimental values for methylated C" are the values shown here the X-ray structure values or the X-ray Structure values optimized with QM/MM for the WT? - if it is the optimized data, than I suggest to add the experimental data uncorrected as well.

This was an oversight from a previous draft: Figure 7 does not contain experimental data, and this has been removed from the manuscript. Inclusion of further data from experiment would make this figure too cluttered and difficult to read.

4. It is difficult to estimate the significance of the changes in structural parameters between different cytosine modifications or different simulation methods, as there are no errors/standard deviations are presented. I would suggest using a set of Xray/NMR structures with the same sequence and/or modifications to create a standard deviation for the different parameters to give the analysis more significance (than I can estimate if a difference of $0.03 \AA$ is of importance or not: "Formyl has a larger effect overall, lengthening N3... H1-N1 and $\mathrm{O} 2 \ldots \mathrm{H} 2-\mathrm{N} 2 \mathrm{H}$-bonds and hence reducing binding by over $3 \mathrm{kcal} / \mathrm{mol}$." Difference in $\mathrm{h}$-bond length from wtC is $0.025 \AA$ 
and $0.049 \AA$, respectively - seems very small, but if all GC wc bp are within of $0.01 \AA$ distance, this would be significant).

It is indeed difficult to estimate the significance of changes in geometry: these static DFT and QM/MM calculations do not yield standard deviations. It would indeed be interesting to extract experimental information to estimate variability across structures, but this would be a whole new project, and is therefore out of the scope of the present work.

Important for: Table $1 \& 2$ - as well important for Fig. 2-5 \& 7, please adjust.

As outlined above, we do not have suitable data with which to adjust these tables and figures.

5. Describe structural/distortion findings in structure/sketches. E.g.: "Iargely due to a strong $\mathrm{H}$-bond between the $\mathrm{H}-\mathrm{O}$ of hydroxymethyl and $\mathrm{O} 6$ of guanine $(\mathrm{H}$... $\mathrm{O}=1.770$ $\AA)$ " for a better understanding of how the structures are supposed to look like.

We have added a figure for this structure to supporting information, and stress that all optimised coordinates have been deposited should readers wish to assess further detail.

6. Formality: p5 first sentence "Following Zubatiuk et al.37," should be "Following Olson et al.37," OR "Following Zubatiuk et al.14,"

We thank the referee for spotting this error, and have corrected it to Following Zubatiuk et al.14,"

7. More information on the Methods and Materials would be appreciated: E.g. How extensive where the simulations/optimizations? What were the energy cutoffs?...

All DFT and QM/MM calculations used Gaussian09 default convergence criteria for SCF calculation and geometry optimisation: a statement to this effect has been added to the methods section. Details of MM calculations are identical to those from our previous work (ref 19): again, a statement has been added to this effect.

Competing Interests: No competing interests.

Reviewer Report 27 March 2015

https://doi.org/10.5256/f1000research.6589.r7803

(c) 2015 Fonseca Guerra C. This is an open access peer review report distributed under the terms of the Creative Commons Attribution License, which permits unrestricted use, distribution, and reproduction in any medium, provided the original work is properly cited. 


\section{Célia Fonseca Guerra}

Department of Theoretical Chemistry and Amsterdam Center for Multiscale Modeling, VU University Amsterdam, Amsterdam, The Netherlands

This paper presents an interesting theoretical studty on epigenetically modified DNA.

Legend of Figure 1: Please include the numbering, so that non-experts can follow the rest of the text.

Page 4: "The presence of a hydroxymethyl slightly weakens the N4-H4...O6" Is there an internal hydrogen bond that is competing with the $\mathrm{N} 4-\mathrm{H} 4 \cdot .006$ hydrogen bond? Please explain.

Page 4 "Formyl has a larger effect overall, lengthening N3...H1-N1 and O2...H2-N2 H-bonds and hence reducing binding by over $3 \mathrm{kcal} / \mathrm{mol}$. " This can easily be understood because N3 and $\mathrm{O} 2$ become less negative due to the electron withdrawing effect. See Chem. Eur. J. 2006, 12: 3032-3042 , Chem. Eur. J. 1999, 5: 3581-3594 and Chem. Eur. J. 2011, 17: 8816-8818 and use these publications to explain these effects on the hydrogen bonds. The epigenetic modifications can be considered to be substituent effects and therefore the changes in the hydrogen bonds can be easily explained.

Table 1: What are the hydrogen bonds lengths meant here? $\mathrm{N} 4 \cdots 06$ or $\mathrm{H} 4 \cdots \cdot 06$. The preference would be $\mathrm{N} 4 \cdot \cdots \mathrm{O} 6$.

Competing Interests: No competing interests were disclosed.

\section{I confirm that I have read this submission and believe that I have an appropriate level of expertise to confirm that it is of an acceptable scientific standard.}

Author Response ( F1000Research Advisory Board Member ) 23 Apr 2015

Lynn Kamerlin

We again thank the reviewer for the time taken to referee the manuscript. Please see our point-by-point response below.

Legend of Figure 1: Please include the numbering, so that non-experts can follow the rest of the text.

Numbering has been added to Figure 1.

Page 4: "The presence of a hydroxymethyl slightly weakens the N4-H4...O6" Is there an internal hydrogen bond that is competing with the $\mathrm{N} 4-\mathrm{H} 4 \cdots 06$ hydrogen bond? Please explain.

The $\mathrm{OH}$ group of hydroxymethyl is found to lie close to $\mathrm{H} 4$, but the lengths reported in Table 1 put this "contact" outside typical ranges of $\mathrm{N}-\mathrm{H}$... O hydrogen bonds, such that we prefer not to refer to a hydrogen bond, but rather the proximity of groups.

Page 4 "Formyl has a larger effect overall, lengthening N3...H1-N1 and O2...H2-N2 H- 
bonds and hence reducing binding by over $3 \mathrm{kcal} / \mathrm{mol}$. " This can easily be understood because N3 and $\mathrm{O} 2$ become less negative due to the electron withdrawing effect. See Chem. Eur. J. 2006, 12: 3032-3042, Chem. Eur. J. 1999, 5: 3581-3594 and Chem. Eur. J. 2011, 17: 8816-8818 and use these publications to explain these effects on the hydrogen bonds. The epigenetic modifications can be considered to be substituent effects and therefore the changes in the hydrogen bonds can be easily explained.

We completely agree that these trends can be understood as substituent effects, and have therefore added both text to reflect this and the suggested references to the relevant section of the Results and Discussion.

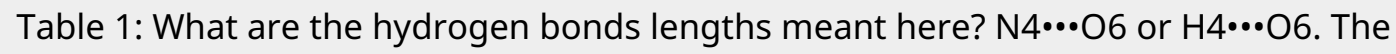
preference would be $\mathrm{N} 4 \cdots 06$.

$H$-bond lengths are reported as $H . . . Y$, since the alternative depends on angular geometry of the $X-H . . . Y$ system. In any case, full coordinates have been deposited as Supporting Information in case interested parties wish to extract $X$... $Y$ distances.

Competing Interests: No competing interests.

The benefits of publishing with F1000Research:

- Your article is published within days, with no editorial bias

- You can publish traditional articles, null/negative results, case reports, data notes and more

- The peer review process is transparent and collaborative

- Your article is indexed in PubMed after passing peer review

- Dedicated customer support at every stage

For pre-submission enquiries, contact research@f1000.com 